\title{
HACIA UNA RESTAURACIÓN DEL SENTIR A PARTIR DE LA FENOMENOLOGÍA DEL CUERPO DE MICHEL HENRY
}

\author{
AGUSTÍN PALOMAR TORRALBO \\ Universidad de Murcia
}

\begin{abstract}
Es terrorífico pensar que nuestra vida es una historia sin sujeto ni héroes, resultado de fuerzas de las que nada sabemos y que se enfrentan ciegamente a nuestras espaldas ${ }^{1 .}$
\end{abstract}

Michel Henry

\begin{abstract}
RESUMEN: El sentir ocupa un lugar destacado en nuestros días. Nuestra época puede ser denominada como la era de la estética. Pero, en ella, el sentir se ha convertido en un medio de dominación y de control tanto de la esfera privada como de la pública. Partiendo de este contexto social, llevo a cabo una investigación acerca de la fenomenología del cuerpo de Michel Henry con el propósito de repensar el sentir como una fuente digna de experiencia subjetiva. Para esta tarea, primero, reparo en la crítica que Henry realiza al idealismo y al objetivismo; y, en segundo lugar, me adentro en la teoría de la subjetividad del cuerpo vivo. Esta teoría puede ser tomada como base de una fundamentación ontológica para pensar originariamente el sentir.
\end{abstract}

PALABRAS CLAVE: fenomenología, cuerpo, subjetividad, inmanencia, carne, reducción, sentir.

\section{Towards a Restoration of the Feeling from Michel Henry's Phenomenology of Body}

ABSTRACT: The feeling takes up an important place nowadays. Our time can be termed as the aesthetic era in which the feeling has become a means of domination and control of both public and private spheres. In this social context, I have done a research into Michel Henry's phenomenology of the body in order to rethink the feeling like a worthy source of subjective experience. Firstly, to carry out this task, I have looked into the criticism that Henry does on objectivism and idealism and, secondly, I have gone into the theory of subjectivity of the living body. This theory can be taken as the basis for an ontological foundation to think originally the feeling.

KEY WORDS: phenomenology, body, subjectivity, flesh, immanence, reduction, feeling.

Ha sido Mario Perniola, profesor de estética, el que ha acuñado el término «sensología» partiendo del concepto marxista de ideología. Si la ideología, como falsa conciencia, impide la posibilidad de que los individuos sean conscientes de sus situaciones reales al ser éstas deformadas por un conjunto de opiniones y de doctrinas ya dadas y no reflexionadas, la sensología puede caracterizarse como lo falso del sentir que reduce y deforma lo vivido a lo meramente sentido.

1 Henry, M., El hijo del rey, Editorial Nuevo Inicio, Granada, 2014, p. 42. 
En efecto, desde el sentir, lo vivido puede ser falso, no porque lo sentido siendo algo falso en sí mismo apunte a lo verdadero como aquello que no puede ser sentido y sí pensado sino porque el sentir mismo, al absolutizarse, cierra, como la ideología, la posibilidad al juicio y al pensamiento. Sin embargo, a diferencia de ésta, en la que el cierre se produce por el sostenimiento dogmático de una idea, en la sensología el cierre se produce en el propio sentir. Según Perniola, el sentir "se halla al amparo de la sospecha $»^{2}$. Ante lo sentido, y ante lo sentido ya no individual sino socialmente, cabe sólo, sin crítica alguna, la aceptación. Pero además, si la ideología situaba a cada individuo o grupo social en un determinado lugar en el espectro de las ideas desde donde lo falso y lo verdadero entraban en liza, la sensología cancela esta posibilidad al serle negado al sentir la posibilidad de ser elevado, identificado y sostenido en la permanencia de las ideas. De esta manera, el dominio del sentir impide la confrontación de todo lo sentido con lo que puede ser o no verdadero. El sentir, bajo la sensología, se guarda bien de que lo sentido trascienda el ámbito del propio sentir: no cabe el reproche, ni el juicio, ni la crítica, ni la confrontación dialéctica con lo sólo sentido; y, sin embargo, en nuestra época, el sentir determina más que nunca la posición de cada cual en la sociedad. Nada une tanto como compartir un sentimiento y nada es, al mismo tiempo, más cambiante que el propio sentir: a un sentimiento sólo puede seguirle otro, y lo que la sensología denuncia es que estos cambios se hacen, al abrigo del poder de toda confrontación de ideas, mediante la simple identificación con unos sentimientos que son traídos y llevados por el poder de los diferentes reclamos afectivos.

Pero, en nuestra sociedad, además de la ideología, el otro centro de poder y de control de las conductas de los individuos está en la burocracia. Si la ideología es el control de las ideas para determinar qué han de pensar los individuos, la burocracia determina cuáles han de ser sus acciones. La burocracia imponiendo un conjunto de esquemas de conducta ya elaborados exime a los individuos de la «disyuntiva entre actuar y no actuar, entre la acción política y la tradición $»^{3}$. La burocracia es una estructura de control, estable y oficial; pero, en nuestra época, el poder de la burocracia se ha visto entrecruzado, solapado e incluso sustituido por el poder de lo que Perniola llama "mediacracia». Literalmente, la «mediacracia» es el poder de los medios. Con este término, alude Perniola al hecho de que el poder en nuestras sociedades venga dado por el control de los medios de comunicación de masas. Ahora bien, lo específico de nuestra época es que tal control se lleva a cabo desde el sentir. El sentir, que pertenece a la esfera de lo privado, individual e inmediato, se ha convertido en el objeto de poder para los medios, de tal manera que ha pasado a ser algo público, social y mediado. Si la burocracia ha pretendido desde siempre el control racional de las conductas individuales desde las instituciones sociales, como certeramente señaló Weber, la mediacracia pretende el control social de

2 Perniola, M., Del sentir, Pre-textos, Valencia, 2008, p. 31.

3 Ibid., p. 32. 
las conductas desde el sentir de las individualidades. No quiere decir esto que la mediacracia no use técnicas de control racionales, como la burocracia, sino que esas técnicas se aplican sobre lo sentido o, mejor aún, que se diseñan no ya para encauzar lo sentido sino para seguir sus directrices ${ }^{4}$. Los medios de comunicación de masas juegan aquí un papel importante en la medida en que no son sólo medios que ponen en relación a una multitud de individuos, ni son sólo medios al servicio de un determinado poder ideológico sino que son los medios a través de los cuales lo sentido, como si fuera asunto relativo a hechos, entra y participa en la formación de las redes sociales. "La mediacracia - afirma Perniola - se afirma basándose en el presupuesto de que todo ha sido ya hecho, dado que todo ha sido ya sentido ${ }^{5}$.

Es nuestra era, podemos afirmar, por tanto, una era estética. El control que antes imponían la ideología y la burocracia hoy se ha trasferido en su mayor parte a la sensología y a la mediacracia estableciéndose mecanismos sociales de control que impiden el libre ejercicio del pensamiento y de la acción. El sentir ha ganado en nuestra era la batalla al control de los pensamientos y las acciones. Por ello, podemos concluir diciendo que el ámbito práctico de la acción y el ámbito teórico de las ideas están hoy subordinados al ámbito estético del sentir. Los conflictos sociales están hoy condicionados no tanto por la confrontación de ideas sino por la confrontación de maneras de sentir:

«Desde los años sesenta se tiene la impresión de que en este terreno es donde se juegan las partidas decisivas, donde se entablan y se rompen las relaciones privadas y sociales, donde se trazan y se cumplen los destinos de los individuos y de las colectividades» ${ }^{6}$.

Queda, sin embargo, abierta la cuestión de si es posible un pensamiento y una acción que tengan su fundamento en el sentir; queda pendiente la pregunta de si es posible recuperar una dimensión del sentir que no lo cierre o cancele como experiencia originaria y generadora de sentido; queda, en definitiva, pendiente el tema si el sentir puede abrir, renovar y refundar un ámbito de experiencia que no venga marcado por la alienación de la sensología y de la mediacracia. Así planteadas las cosas, y más allá del ámbito de la antropología marxista en el que Perniola piensa el sentir, nosotros vamos a profundizar en él para ver si puede aprehenderse de tal manera que, sin perder la vida que el sentir lleva dentro, pueda superarse la vulnerabilidad que marca la comprensión que de facto tenemos de él en nuestra época.

Para ello, ahora nuestro trabajo, tras esta introducción, va a girar hacia la fenomenología con la intención de describir la experiencia del sentir en su sentido originario, esto es, desde el lugar mismo donde se produce todo sentir: el cuerpo. Seguiremos, para ello, las indicaciones de aquella fenomenología que con más intensidad ha hecho de la experiencia del cuerpo, del sentir y de la

\footnotetext{
Cfr., Ibid., p. 33.

Ibid., p. 34.

Ibid., p. 27-28.
} 
afectividad el centro mismo de su pensar: nos referimos a la fenomenología de Michel Henry. La problemática del cuerpo cubre toda la trayectoria intelectual de Henry y las referencias al cuerpo están presentes en todos sus trabajos. Sin embargo, en esta trayectoria hay que señalar dos momentos fundamentales: uno en el comienzo de su camino en la fenomenología y otro al final del mismo. El primero, corresponde a su libro Philosophie et phénoménologie du corps. Essai sur l'ontologie biranienne que fue publicado en 1965, pero que fue redactado, como el mismo Henry indica, entre los años 1948-1949 y que correspondió originariamente a un capítulo de L'essence de la manifestation ${ }^{7}$. El segundo momento viene representado por su libro Incarnation. Une philosophie de la chair, publicado en el año 2000, dos años antes de su muerte, y en el cual se produce un giro hacia una fenomenología teológica de la carne. De estos dos textos, nosotros nos centraremos exclusivamente en el primero por ser más cercano a una estricta filosofía del cuerpo, aunque al término de la exposición pueda advertirse de qué modo la fenomenología del cuerpo de Michel Henry, en sus últimas obras, hunde sus raíces en las entrañas del cristianismo ${ }^{8}$.

Pues bien, de entrada hay que decir que es interesante esta obra de Henry porque en su lectura aparece el esfuerzo del autor por elaborar una fenomenología del sentir del cuerpo cuando, todavía, no se había publicado Ideas II de Husserl - la publicación del segundo volumen de Ideen tuvo lugar en 1952-, y cuando el autor, como él mismo reconoce en el Prefacio, desconocía las investigaciones de Merleau-Ponty ${ }^{9}$. Dejando, por ello, a un lado la relación de Henry con Merleau-Ponty ${ }^{10}$, vamos a comentar brevemente la relación de este libro de Henry con la fenomenología de Husserl.

Llama la atención, en primer lugar, que salvo en el Prefacio no haya referencias explícitas a Husserl, aunque conforme uno va avanzando en la lectura de este libro, va viendo que, a pesar de que esta obra es profundamente crítica con la fenomenología de Husserl, toma, sin embargo, de ella los términos que la roturan en su especificad. Así, por ejemplo, el tema de la reducción y el tema de la correlación entre inmanencia y trascendencia ${ }^{11}$, claves en la fenomenología

7 Cfr. Henry, M., Filosofía y fenomenología del cuerpo. Ensayo sobre la ontología de Maine de Biran, Sígueme, Salamanca, 2007, p. 21.

8 En este sentido pocas páginas de los textos del fenomenólogo francés provocan una defensa más clara del cuerpo como lugar de la subjetividad que aquella con la que finaliza Yo soy la verdad. Aquí Michel Henry describe ejemplarmente cómo el objetivismo moderno ha expulsado del cuerpo el ser el modo en el que la vida Invisible se torna visible en el mundo (cfr. Henry, M., Yo soy la verdad, Sígueme, Madrid, 2001, p. 135).

9 Cfr. Henry, M., Filosofía y fenomenología del cuerpo, op. cit., p. 21.

10 Para la crítica posterior de Henry a Merleau-Ponty véase: GARCía JARAMA, J. C., Finitud, carne e intersubjetividad, Instituto Teológico San Idelfonso, Toledo, 2007, pp. 352-354.

11 El tema de la relación entre inmanencia y trascendencia es central y recurrente en los estudios sobre Husserl. Ya en 1959 Wilhelm Szilasi, discípulo fiel a la concepción trascendental de la fenomenología, hizo de la trascendencia y, por tanto, de la inmanencia el problema mismo de la fenomenología (cfr. SzILASI, W., Introducción a la fenomenología de Husserl, Amorrortu, Buenos Aires, 2003, pp. 146-158.). 
husserliana y en toda fenomenología, son también claves para la elaboración de la fenomenología del cuerpo. Aunque Husserl da el método y los conceptos fundamentales para la elaboración de la fenomenología, será Maine de Biran el filósofo que Henry tome como guía para la investigación ontológica sobre el cuerpo. Pero hay que resaltar que Henry hace una lectura tan vigorosa de los textos de Maine de Biran, a través de la lente de la fenomenología husserliana, que de ella surgirán nítidamente los contornos de la propia fenomenología del pensador francés. Profundicemos ahora en la confrontación entre Husserl y Henry atendiendo al concepto donde se pone en juego el alcance de toda fenomenología: nos referimos, evidentemente, al concepto de reducción.

\section{IDEALISMO, REDUCCIÓN Y VIDA}

En el citado Prefacio, escrito en 1987, con ocasión de la segunda edición del libro, Henry deja claro lo que le movió a realizar una investigación en torno al cuerpo: «Mi propósito en él era establecer frente al idealismo el carácter concreto de la subjetividad, mostrando para ello que dicha subjetividad coincide con nuestro propio cuerpo ${ }^{12}$. Este presupuesto, que atravesará toda la fenomenología de Henry, establece la ecuación entre cuerpo y subjetividad, rompiendo de esta forma la tendencia de la metafísica racionalista moderna que para él, como para Heidegger, tiene su culminación en el objetivismo moderno y en la manifestación de ese objetivismo en la sustitución del pensamiento por la ideología y por esa "Objetividad monstruosa de la técnica» ${ }^{13}$. Pero, más que a Heidegger, Henry parece aproximarse a Husserl en la medida que comparte con él la tesis de que la crítica al objetivismo pasa por recuperar la vida, esa vida que Husserl encontrará, en la madurez de su pensamiento, tanto en la concepción de la subjetividad trascendental, analizada como una subjetividad viva, como en la concepción de ese mundo ante-predicativo que, entendido como plexos de experiencias, conforma el «mundo de la vida» ${ }^{14}$. Sin embargo, a pesar de esta cercanía, en este Prefacio aparece una referencia crítica explícita a Husserl. Ahí se nos dice que la expresión central, para una fenomenología del cuerpo, de «experiencia interna transcendental» no debe tomarse en el sentido dado por Husserl en las Meditaciones cartesianas $^{15}$. Es importante esta observación referida a este libro de Husserl, porque Henry, seguramente, advirtió la profunda afinidad entre su propuesta fenomenológica y la del propio Husserl en esa nueva revisión de la fenomenología transcendental que hizo en las Meditaciones cartesianas. Veamos en qué sentido decimos esto.

12 Henry, M., Filosofía y fenomenología del cuerpo, op. cit., p. 21.

13 Ibid., p. 22

14 Que el asunto de la fenomenología se juega, precisamente, en la síntesis entre mundo y vida ha sido destacado entre nosotros en: GARCía-BARó, M., La práctica de la fenomenología, Trotta, Madrid, 1999, pp. 178-183.

15 Cfr. Henry, M., Filosofía y fenomenología del cuerpo, op. cit., p. 22. 
Husserl partiendo de Descartes y Henry partiendo de Maine de Biran desarrollarán sus propuestas fenomenológicas a partir del ego. Recuérdese que Husserl sigue en las Meditaciones cartesianas el camino para la reducción conocido como "cartesiano», los otros dos serán el camino del mundo de la vida y el de la psicología ${ }^{16}$. Sin embargo, las direcciones del análisis entre Husserl y Henry son opuestas: mientras que para Husserl el ego será el ego cogito a través del cual se descubre, tras la reducción, la subjetividad trascendental como subjetividad del ego reflexivo, para Henry el ego será el propio cuerpo o, más certeramente, la subjetividad coincidente con el cuerpo. Para Husserl, la reflexión fenomenológica hace posible que de la experiencia de mi yo natural y de mi vida psíquica, mediante la reducción, obtengamos «la experiencia fenomenológico-trascendental de mí mismo» ${ }^{17}$. Henry ve problemática esta concepción de la reducción fenomenológica. La cuestión no está, primeramente, en el modo en el que se ejecuta ni en lo que queda desconectado en la aplicación de la misma - lo trascendente - sino en que la reducción es la llave para abrir toda experiencia trascendental y en que tal apertura presupone la elevación de la experiencia natural a la subjetividad trascendental, lo cual sólo es posible por la capacidad de la subjetividad misma para traer a presencia de sí lo trascendente que está fuera de ella. Por ello, podemos decir que, en la fenomenología transcendental, la reducción es la llave para abrir cualquier campo de presencia. Pero esta afirmación, a juicio de Henry, supone un problema mismo para la vida: la vida, entonces, sólo puede mostrarse desde la presencia que abre la reducción en la subjetividad trascendental. La reducción, dice Henry, abre «un campo de presencia donde la vida pueda mostrarse ${ }^{18}$. Pero la vida, para el fenomenólogo francés, es aquello que no necesita de la reflexión para mostrarse o, más técnicamente, la vida se descubre en el ego no través del cogito que realiza la reducción sino en sí misma: la vida se muestra, aparece desde y en sí misma. La vida es autodonación, un «hecho primitivo» que no puede ser reducido para verse en el campo de presencia abierto por el cogito. La experiencia interna al ego no puede ser ya, por ello, el producto, el residuo, de la práctica de la reducción sino un a priori absoluto del que sólo sabemos en una experiencia inmediata. Y, sin embargo, a esta experiencia, de alguna manera, también podríamos adjetivarla de «trascendental» en la medida que es condición de posibilidad de toda otra experiencia del sujeto.

Vistas las cosas en este marco, comprendemos el fundamento de la crítica de Henry a la fenomenología husserliana: la reducción, como reconducción de la experiencia a su fuente trascendental, señala el poder de un ego que puede erigirse en clarificador de toda experiencia, también de la experiencia de la vida. La reducción señala al poder que tiene el sujeto sobre la vida, y, en la

16 Cfr. KeRn, I., «Los tres caminos hacia la reducción fenomenológica trascendental en la filosofía de Edmund Husserl» en Serrano de Haro, A. (ed.), La posibilidad de la fenomenología, Editorial Complutense, Madrid, 1997, pp. 259-293.

17 Husserl, E., Meditaciones cartesianas, Tecnos, Madrid, 1986, p. 36.

18 Henry, M., Filosofía y fenomenología del cuerpo, op. cit., p. 22. 
perspectiva de la metafísica idealista y del objetivismo moderno de la ciencia, ello implica que el sujeto tiene el control sobre la propia vida. Pero, la vida, así lo manifiesta Henry, no puede ser elucidada esencialmente ni por una metafísica racionalista ni por una ciencia particular como la biología. Hay un saber previo y primordial acerca de la propia vida y como ésta se experiencia en el cuerpo. «No esperamos — dice gráficamente Henry-a haber leído las últimas obras de biología para correr, saltar, caminar o levantar los brazos» ${ }^{19}$. Y, sin embargo, nuestra experiencia de la vida es la que viene dada en el horizonte de la metafísica y de la ciencia. ¿Cómo podríamos volver a la experiencia originaria del cuerpo? ¿Cómo podríamos retornar a esa esfera donde la experiencia del cuerpo es experiencia de la vida?

Este camino de retorno hacia lo originario podemos calificarlo como «reducción ${ }^{20}$ si entendemos que la reducción es sencillamente el camino o la vuelta atrás que nos lleva de regreso a los fenómenos originarios. Para la fenomenología de Henry el lugar de tales fenómenos es el propio cuerpo. La reducción ha de llevarnos al lugar donde se producen las primeras y más básicas experiencias subjetivas. Ahora bien, situados ya en el cuerpo, no es fácil distinguir entre lo que es originario y lo que no lo es. El sustrato de experiencias que han sido acumuladas por la historia de nuestro pensar metafísico y científico hace difícil separar las experiencias más fundamentales y propias del cuerpo de la experiencias derivadas que se han forjado en el contacto del cuerpo con el mundo. Para aclarar este punto tenemos que hacer un breve análisis fenomenológico. De entrada observamos que la reducción puede tener diverso alcance de aplicación en lo que llamamos «experiencia del cuerpo». En primer lugar, como ya hemos indicado, la reducción tiene que operar sobre la concepción del cuerpo como una entidad física; en segundo lugar, sobre la concepción del cuerpo como ser vivo natural; y, por último, sobre el cuerpo como un cuerpo humano, como el cuerpo de un ser vivo con características propias que son irreductibles al cuerpo dado como un simple ser natural. Pues bien, lo que tienen en común estos diferentes sustratos de experiencias del cuerpo es que la experiencia recae fuera del propio cuerpo. La experiencia tanto científica como ordinaria del

$19 \quad$ Ibid., p. 28.

20 El término «reducción» es usado varias veces a lo largo del trabajo. Henry también utiliza, en muchas ocasiones, el término «abstracción», el cual en las Investigaciones lógicas desempeñaba las veces de la epojé y de la reducción en un contexto, como se sabe, todavía no trascendental. La importancia de este contexto que surge en torno a la primera edición de las Investigaciones Lógicas ha sido resaltado en: García-BARó, M., Teoría fenomenológica de la verdad. Comentario continuo a la primera edición de Investigaciones lógicas, de Edmund Husserl, Universidad Pontificia de Comillas, Madrid, 2008, pp. 9-13. Pero debe tenerse presente también que, precisamente, es Maine de Biran el que usa el término «abstracción» para nombrar el acto mediante el cual, según sus propias palabras, «el yo humano se distingue y se separa de todo lo que no es él, de todo lo que no entra inmediatamente en el sentimiento de su existencia propia, de todo lo que no es condición esencial, no de su existencia objetiva, pero sí del sentimiento o la conciencia actual que tiene de ella» (Maine de Biran, Nuevos ensayos de antropología, Sígueme, Salamanca, 2014, p. 14.). 
propio cuerpo recae en una estructura trascendente, es decir, en una estructura que se forma en un plexo de relaciones que se alejan de la experiencia originaria del cuerpo. La reducción, como suspensión de todo aquello que es trascendente y como vuelta a lo que es inmanente, ha de hacer posible que esa vuelta a los fenómenos originarios no contenga ningún elemento trascendente. Pero, este camino negativo hacia la búsqueda de lo originario, esta vuelta de tuerca de aquella subjetividad que está mezclada con la experiencia del mundo, encuentra en el término de su práctica lo positivo y originario que buscaba: la experiencia del cuerpo como la experiencia de lo que ya no puede ser trascendido, esto es, la experiencia como algo dado en la inmanencia del propio cuerpo. La fenomenología radical de Henry muestra que el cuerpo inmanente, el residuo de ese cuerpo que nos devuelve lo originario y, sin embargo, olvidado en el transcurso de la constitución de la propia experiencia del cuerpo en el horizonte de la tradición de nuestro pensamiento, coincide con la subjetividad misma. Y, en la medida que ella es la condición primera y absoluta de toda otra experiencia puede ser adjetivada como «interna trascendental». Pero, después de lo dicho, vemos cómo esta expresión ya tiene otro alcance y otro significado que la homóloga expresión de Husserl en las Meditaciones cartesianas.

Que el cuerpo es en la inmanencia absoluta es la tesis más importante de la fenomenología de Henry, y donde se nos muestra su nudo aporético más difícil de aceptar. Aunque sabemos que Husserl en los diversos ensayos que hizo de fundamentación de la fenomenología estableció diversos caminos para la reducción, y aunque sabemos que no podemos identificar sin más la reducción fenomenológica con la reducción eidética ${ }^{21}$, ésta sigue teniendo un papel fundamental en el entendimiento del propósito de la fenomenología trascendental $^{22}$. Mediante esta reducción el sujeto que hace fenomenología deja de tener presente lo concreto, lo dado aquí y ahora, y sitúa su mirada en lo esencial eidético. La reducción eidética nos descubre cómo el mundo está trabado, estructurado o constituido por ideas o esencias, es decir, nos descubre cómo lo dado concreto se mantiene vertebrado por algo que, perteneciendo intrínsecamente al mundo, sin embargo, no forma parte de la experiencia del mundo. Pero, ¿qué papel desempeñan las ideas? ¿Podemos tener experiencia de las ideas? La fenomenología trascendental de Husserl afronta directamente estas preguntas que provienen de la historia misma de la metafísica. Detengámonos un momento aquí.

21 Cfr. SAn Martín, J., La estructura del método fenomenológico, UNED, Madrid, 1986, p. 26-39.

22 Una cuestión que queda pendiente es si el paso de las investigaciones metodológicas en Ideas I a las investigaciones de las diferentes capas de constitución que forman la realidad en Ideas II conlleva un cambio de posición respecto a la cuestión de las ideas y de la reducción eidética. No es esta cuestión en sí misma fácil de dilucidar, porque, en el modo en el que aquí ha sido planteada, la delimitación misma de esas capas o estructuras de la realidad que investiga Ideas II exige no abandonar la reducción eidética si que tales capas constitutivas de la realidad se tienen por esenciales. 
Las ideas o esencias, en la tradición metafísica que se remonta a Platón y que culmina en Hegel, hacen posible la constitución ontológica del mundo y también su conocimiento. La idea, como ha reiterado Heidegger, es lo que permite ver o vislumbrar «lo que cada ente es y cómo lo es» ${ }^{23}$. La idea es, tomando la lectura que Heidegger hace de Platón, lo que hace posible dejar ver, al dejar pasar la luz, cómo son los entes. La idea es fundamento ontológico y gnoseológico de todos los entes. Heidegger identificará, por ello, la idea con el ser en el comienzo de la metafísica. Pues bien, lo interesante es darse cuenta de que las ideas o las esencias en Husserl, más allá de la cuestión de que Husserl entre o no dentro de esa historia de la metafísica, cumplen cabalmente el papel que tuvieron en la metafísica: el de constituir la realidad y el de hacer posible su conocimiento. La reducción fenomenológico-eidética nos descubre la constitución última de la realidad en su esencialidad. La actitud fenomenológica que pone su atención y su esfuerzo en la reducción eidética pone en evidencia cómo son los entes en la claridad y presencia del sujeto ${ }^{24}$.

Pues bien, la metáfora que Henry suele utilizar para hablar de la subjetividad concreta del cuerpo no deja lugar a dudas respecto a los resultados de la aplicación de la reducción eidética: la vida, la vida que es la materia del cuerpo, ya no es luz sino Noche. «En lo invisible de la Noche, sin embargo, —dice Henry- la vida estrecha su abrazo, nos devuelve a cada uno de nosotros a sí mismo, a lo indubitable de su cuerpo ${ }^{25}$. La vida es lo invisible, aquello que no se deja transparentar a través de la reducción eidética. La vida es aquello que no se deja clarificar por las ideas, es lo absoluto, lo inmanente y lo invisible, aquella materia que no puede ser reconducida a sí misma para hacerse diáfana al sujeto. La vida señala, de este modo, el límite donde puede ser aplicada la propia reducción fenomenológica como reducción eidética. Este es el núcleo aporético que está en la base del pensamiento de Henry, y el motivo que hace siempre difícil su aceptación para un pensamiento que tome como motivo fundamental de su quehacer la dilucidación y la clarificación de la realidad a través de las ideas. Tal aporía nos sitúa ante un dilema: o bien la vida no tiene como el mundo estructura eidética, o bien esa estructura es desconocida para la subjetividad humana como subjetividad finita. Un cuerno del dilema nos lleva al irracionalismo, el otro, a la teología. Son estas consecuencias, que nosotros aquí no podemos explorar, las que nos sitúan en el contraste mismo entre una fenomenología que trata de los fenómenos como fenómenos sujetos a la razón y una fenomenología que los trata como no teniendo en la razón su razón de ser. Para seguir nuestro trabajo retengamos, sencillamente, la tesis de la centralidad de la experiencia subjetiva del cuerpo. Henry, volviendo a la cita

23 Heidegger, M., De la esencia de la verdad, Herder, Barcelona, 2007, p. 59.

24 El núcleo de la tensión entre una fenomenología eidética y una fenomenología que renuncia al poder clarificador de las ideas ha sido tratado en: Palomar Torralbo, A., «Apariencia, idea y cuerpo: un prólogo platónico para la fenomenología de la vida de Michel Henry» en Investigaciones fenomenológicas, n 10, 2013, pp. 141-156.

25 Henry, M., Filosofía y fenomenología del cuerpo, op. cit., p. 22. 
anterior, expone esta tesis diciendo que el cuerpo es lo indubitable, no porque podemos verlo con la evidencia de lo que ya no puede generar más dudas sino porque lleva en sí un poder que no puede ser enmascarado, retenido y visto por el propio sujeto. Así, el poder de la vida se manifiesta en el cuerpo sin mediación alguna, porque la vida, la vida como lo absoluto, no requiere más que de sí misma para mostrarse sin que el sujeto pueda disponer de llave alguna para hacerla aparecer.

\section{ONTOLOGÍA, SUBJETIVIDAD Y CUERPO}

La demarcación de la fenomenología de Henry respecto a la de Husserl ha dado como resultado que el problema del cuerpo haya de plantearse en la esfera de la inmanencia absoluta. Esto significa que el ser de la vida sólo se da en el aparecer mismo sin que tenga que recurrirse al poder de clarificación del sujeto en las ideas para hacerla aparecer. La consecuencia ontofenomenológica de esta tesis es que ser y aparecer coinciden, esto es, que ser y aparecer, en la inmanencia absoluta, remiten en su correlatividad a una misma realidad que llamamos «fenómeno». Sin el poder del sujeto para hacer aparecer la vida, la fenomenología tiene como tarea un dejar mostrar el fenómeno sin la mediación de algo previo a ella misma, como son las ideas ${ }^{26}$. Pero, ¿cómo ha he entenderse ontológicamente esta subjetividad concreta que se identifica con el cuerpo? ¿Cómo han de entenderse las categorías de esta ontología? ¿Podemos incluso hablar de categorías en esta inmanencia donde la opacidad es absoluta? Son estas las cuestiones que se derivan de aquel núcleo aporético que señalábamos más arriba. Sin embargo, una respuesta negativa de entrada implicaría suspender el derecho del quehacer mismo de la filosofía fenomenológica. La empresa es difícil, pero Henry, tomando como guía las reflexiones ontológicas de Maine de Biran, pretende abrir un camino en medio de esta aporía. Veamos cómo.

En efecto, Maine de Biran puede conducir una investigación ontológica en el seno de la subjetividad, según M. Henry, en la medida en que hace una distinción radical entre el ser transcendente y el ser inmanente transcendental que él denomina, siguiendo la tradición cartesiana, cogito. Ahora bien, la diferencia con respecto a Descartes está en que entiende este cogito no como un acto reflexivo e intelectual sino como «una acción, un esfuerzo, un movimiento» ${ }^{27}$. Si el primer principio de la filosofía cartesiana era «Pienso, luego, soy (cosa o substancia pensante)» ${ }^{28}$, ahora, para Maine de Biran, es: «Actúo, quiero o

26 Los problemas metodológicos de esta fenomenología radical han sido han sido tratados en: Henry, M., «El método fenomenológico» en Fenomenología material, Ediciones Encuentro, Madrid, 2009, pp. 97-182.

27 Henry M., Filosofía y fenomenología del cuerpo, op. cit., p. 37.

28 Maine de Biran, op. cit., p. 74. 
pienso la acción, luego me sé causa, luego soy o existo realmente como causa o fuerza ${ }^{29}$. Paul Ricoeur, en este sentido, ha dicho que «Maine de Biran es el primer filósofo en haber introducido el cuerpo propio en la región de la certeza no representativa ${ }^{30}$.

Pues bien, de este modo, las categorías, como formas en la que el ser se dice, son categorías del ser inmanente, pero estas «nociones primeras», como las llama Maine de Biran, son encontradas en la experiencia que el sujeto tiene de sí no en sus ideas sino en su actividad, su movimiento o su disposición. Las categorías, en la subjetividad absoluta, antes que presentársenos como ideas, se nos presentan en un modo de existencia anterior. "Deducir las categorías significa - dice Henry - pues, para Maine de Biran, mostrar que estas tienen un modo de existencia anterior a aquel en virtud del cual se nos presentan en forma de ideas propiamente dichas, y que es un modo de existencia más originario donde tienen su fundamento ${ }^{31}$. La deducción de las categorías no pretende mostrar cómo éstas, metafísicamente, se derivan de los juicios, porque la verdad de la subjetividad absoluta, como insiste Henry, es antepredicativa, ni tampoco pretende mostrar, trascendentalmente, que las categorías están referidas a los fenómenos, porque el fenómeno no es algo independiente de las categorías mismas sino que pretende mostrar el originen mismo de las categorías en la experiencia que la subjetividad tiene de sí. La deducción de las categorías ha de mostrar el origen de nociones como «sustancia», «unidad», «identidad», "causalidad», etc.

Cuando se llevan estas nociones al fondo de la subjetividad, se advierte que su origen no está en las ideas, tal y como estas se entendieron en el racionalismo y el empirismo, sino en el ejercicio de la propia subjetividad como una facultad. Si la tradición de la metafísica idealista afirma que no puede ejercerse ninguna facultad sin conocerla, la filosofía biraniana afirma que tampoco puede conocerse la subjetividad sin ejercerla ${ }^{32}$. Por ello, Henry, releyendo más fenomenológicamente el pensamiento de Maine de Biran, dirá que más que de una deducción, para las categorías así entendidas, hemos de hablar de una reducción: la reducción del concepto de la categoría entendida como idea al origen de dicha idea en el ejercicio de la reflexión de la subjetividad, esto es, en su ejercicio o actividad. Las categorías no son así las condiciones formales de la posibilidad de la experiencia empírica o trascendente sino la condición de la condición de esa experiencia. Por ello, dirá Henry, en una interpretación que se acerca mucho, en este caso, a la lectura que hace Heidegger de la Crítica de la razón pura, que «la categoría es la verdad originaria misma y esa verdad es la condición de posibilidad de toda experiencia, la posibilidad ontológica originaria $»^{33}$. Pero, podríamos preguntarnos si a estas posibilidades ontológicas

\section{$29 \quad$ Ibid.}

30 Ricoevr, P., Sí mismo como otro, Siglo xxi, Madrid, 1996, p. 356.

31 Henry, M., Filosofía y fenomenología del cuerpo, op. cit., p. 49. El subrayado es mío.

32 Cfr., Ibid., p. 50.

$33 \quad$ Ibid., p. 57. 
cabría llamarlas entonces «categorías». La respuesta de Henry, apoyada por los textos de Maine de Biran, es afirmativa en tanto que ellas son las disposiciones primeras en las que se muestra ontológicamente la subjetividad y las condiciones últimas de posibilidad de toda otra experiencia. La lectura que Henry hace del análisis de Maine de Biran muestra que hay un análisis ontológico de este tipo para cada una de las diferentes categorías: para la categoría de sustancia, de unidad, de identidad, o, más importante en el sistema biraniano, de causalidad. En estos análisis particulares se muestra que hay una disposición de la subjetividad que constituye la categoría como idea en el ejercicio y en el esfuerzo del ego.

Por tanto, desde la teoría inmanente de las categorías, llegamos a la tesis de que el ego, el cogito, no es, originariamente, un ser trascendente para sí mismo ni tampoco un ser constituido en su vida inmanente por ideas sino un ser que es disposición, posibilidad y poder. El ser del cogito antes que estar constituido por ideas es constituido por el esfuerzo. «Es el ser del esfuerzo, su modo originario de presencia ante sí, lo que constituye la ipseidad del yo», sentencia Henry $^{34}$. Aquí Henry sigue la tesis de Maine de Biran para el cual el sentido inmanente del esfuerzo viene dado como «apercepción interna inmediata», la cual es el resultado de despojar en toda operación intelectual al yo de todo aquello que lo convierte en un ser pasivo ${ }^{35}$. De este modo, la vuelta a la inmanencia radical descubre el modo en el que el cogito se hace presente a sí mismo en la inmediatez de su experiencia, lo cual se vivencia en el modo reflexivo de la acción y no del pensamiento intelectual. Vivimos y experienciamos nuestra subjetividad principalmente no como un "yo pienso» sino como un "yo actúo» o bien un «un yo puedo actuar». La filosofía de Maine de Biran es, por ello, «una teoría ontológica de la acción » ${ }^{36}$. Si alejáramos la vivencia de que el cogito se experiencia como actividad y lo concibiéramos sólo bajo una constitución eidética, abandonaríamos la esfera originaria de lo que somos. Este poder para la acción o esta acción que se hace poder está ya en el cuerpo. La subjetividad, antes que subjetividad que produce cogitaciones y relaciones entre cogitaciones, está presente en el cuerpo que tiene como a uno de sus poderes fundamentales también el producir esas cogitaciones; pero, en modo alguno, es ese su único poder. El ser fenomenológico primero no está en lo constituido por la

\footnotetext{
34 Ibid., p. 68.

35 Cfr. Maine de Biran, op. cit., p. 26-27.

36 Henry, M., Filosofía y fenomenología del cuerpo, op. cit., p. 89. Aquí radica también para Maine de Biran el hecho de que ser y aparecer coincidan, de que el fenómeno y la realidad sean lo mismo. Efectivamente, si el yo se identifica con el sentimiento inmediato de la fuerza, entonces la distinción, dice Maine de Biran, entre fenómeno y noúmeno, entre lo relativo y lo absoluto "queda sin objeto ni valor», pues el principio de la fuerza «no puede constatarse ni pensarse a sí mismo como actuante y libre sin ser en sí, o virtualmente, lo que sabe, lo que piensa ser en su existencia actual» (MAINE DE BIRAN, op. cit., p. 76). En definitiva, ser y aparecer coinciden en la experiencia subjetiva del cuerpo en la ontología biraniana porque el ser no puede pensarse sino en su manifestación en el ejercicio de una fuerza o de un poder que siempre renace como condición última de toda otra manifestación del ser.
} 
subjetividad, que ya es de alguna manera algo trascendente, sino en el poder constituyente de la misma, poder que pertenece a la inmanencia que no puede ser trascendencia, es decir, a la inmanencia absoluta. Esta es la tesis capital de la fenomenología de Henry. Veamos, para terminar este epígrafe, cómo es enunciada por él:

«El ser fenomenológico (es decir, originario, real y absoluto) del cuerpo es, pues, un ser subjetivo. Con ello se afirma asimismo la inmanencia absoluta del cuerpo, afirmación que implica el rechazo de todos los análisis presididos por la presuposición de que el cuerpo sea en su ser originario algo trascendente...» ${ }^{37}$.

\section{El SENTIR, EL MOVIMIENTO Y LA PASIVIDAD}

Si lo anterior es cierto, entonces, en la esfera de la inmanencia absoluta de la subjetividad, el conocimiento primero ya no puede venir dado por la reflexión intelectual sino por el modo como se muestra la propia subjetividad. Pues bien, el cuerpo, como subjetividad, se nos da a través del movimiento. En la inmanencia absoluta, el ser de la subjetividad es movimiento que nos es dado sin mediación alguna en el cuerpo. Esto podría entenderse de la siguiente manera: el movimiento de nuestro cuerpo es lo primero y el conocimiento que tenemos de ese movimiento es algo derivado o secundario. Efectivamente, el movimiento de mi mano, o de cualquier parte de mi cuerpo orgánico, es anterior a cualquier idea sobre el movimiento o a cualquier reflexión intelectual. Sin embargo, que el conocimiento es inmediato en el movimiento de mi cuerpo puede entenderse más radicalmente de la siguiente forma: nuestro cuerpo sólo puede conocerse en el movimiento de la subjetividad. En la esfera de la inmanencia absoluta, el saber del cuerpo es el saber que viene dado por el movimiento de la subjetividad en el cuerpo. Puede afirmarse, en este sentido, que ser es ser movimiento. Puede Henry, por ello, abrir el capítulo que lleva por título «El movimiento y el sentir» con la siguiente afirmación: «La teoría ontológica del movimiento coincide con la teoría ontológica del cuerpo ${ }^{38}$.

Ahora bien, este ser que es movimiento se nos muestra y nos aparece como sentir. El sentir se constituye en el movimiento del cuerpo. El cuerpo se confunde con el acto del sentir. El sentir es conocimiento inmediato. Sin embargo, hacer manifiesto esto no es fácil. Si partimos del hecho de que la sensación está en el comienzo mismo de la construcción del conocimiento, entonces tendremos que admitir que en el conocimiento más básico ya hay una cierta mediación, a saber, la del estímulo que viene de fuera del sujeto y sin la cual no habría sensación. Que el conocimiento comience con la sensación desmiente que el conocimiento primero y fundamental sea inmanente al cuerpo. Pues bien, el

$37 \quad$ Ibid., p. 95.

38 Ibid., p. 119. 
análisis de Henry, siguiendo el principio fenomenológico de la desconexión de toda experiencia trascendente, muestra que la sensación no anula el carácter ontológico del movimiento inmanente del cuerpo sino que lo presupone. En efecto, las sensaciones hay que entenderlas como índices del movimiento del proceso subjetivo del sentir. Las sensaciones, podemos decirlo así, nos muestran el ámbito óntico del sentir, pero señalan la dirección ontológica hacia la que tenemos que orientar nuestra investigación del sentir. Aun perteneciendo al ámbito óntico, la sensación puede indicar el ser mismo de la subjetividad porque la sensación marca un sentir en el movimiento del cuerpo sin que en ese sentir esté todavía elevado a representación o idea en el conocimiento ${ }^{39}$.

Pero, además, la diferencia ontológica entre el sentir particular de la sensación y el sentir general del movimiento del cuerpo explica por qué nuestro cuerpo se mueve y se dirige para tener la experiencia de las sensaciones. La raíz de todos nuestros sentidos está en el cuerpo, en ese cuerpo que es poder, movimiento y sentir. Sin este poder, que Henry califica de «puro» siguiendo a Kant pero con un sentido completamente inverso al suyo, nuestro cuerpo no se movería ni se dirigiría hacia las propias sensaciones. ¿Por qué aprehendemos sensaciones en nuestro cuerpo? Henry encuentra que es el cuerpo vivido como movimiento en la esfera radical de su inmanencia lo que hace comprensible en última instancia aquel amor a las sensaciones del que ya hablara Aristóteles al comienzo de la Metafísica. Pero, siguiendo con la descripción fenomenológica, las sensaciones apuntan ontológicamente al movimiento de la subjetividad en un sentido muy preciso: sólo en el movimiento del cuerpo se produce la unidad de constitución de las diversas sensaciones. Si el análisis óntico nos muestra las diversas formas sensitivas, los diversos tipos de sensaciones, el análisis ontológico nos muestra cómo las sensaciones requieren del movimiento del propio cuerpo. Así, por ejemplo, la sensación visual depende de un movimiento particular, a saber, el de la mirada. Veamos un ejemplo aducido por Henry:

«Este movimiento es el que me procura el color amarillo de la pared de mi habitación situada ante mí; luego atravesando la ventana, los tonos de las ramas secas invernales del parque y, en lo alto, el azul pálido del cielo» ${ }^{40}$.

Este sencillo ejercicio de descripción fenomenológica muestra que la sensación del color depende de un movimiento de mi cuerpo. Pero, también nos muestra que no ya cada una de las sensaciones particulares de color sino la unidad constituida de esa serie de sensaciones visuales es posible en virtud del movimiento subjetivo/corporal de la mirada. Es el movimiento de la mirada el que hace posible la constitución de una unidad de sensaciones. Esta unidad no se realiza mediante una especie de asociaciones de ideas de las diferentes sensaciones sino por la mediación del poder de movimiento de nuestra subjetividad. Es en ella en donde radica la unidad originaria constituyente de las sensaciones. Así, en el ejemplo propuesto, la mirada, y no la sensación visual,

39 Cfr. Ibid., pp. 121-122.

40 Ibid., p. 121. 
es el acto de la subjetividad de nuestro cuerpo. Análisis fenomenológicos análogos pueden realizarse para las sensaciones olfativas, auditivas y táctiles. Pero, al igual que Husserl en Ideas $I I^{41}$, Henry destaca, sobremanera, el movimiento subjetivo correspondiente al sentido del tacto. Ya, en este sentido, había resaltado Ricoeur que en Maine de Biran la «aptitud - de la carne- para sentir se manifiesta por privilegio en el tacto » ${ }^{42}$. Más que en los demás sentidos, en el tacto apreciamos cómo el sentir está ligado intrínsecamente al movimiento de mi cuerpo y cómo la unidad constituida de las diferentes sensaciones viene dada por la resistencia de las cosas. En efecto, respecto a las sensaciones táctiles, la experiencia muestra que su unidad viene dada del hecho de que todo lo tocado ofrece una resistencia al cuerpo que toca. Por ello, es en el tacto, en su sentir, donde la diferencia entre la inmanencia del cuerpo y la trascendencia del mundo se hace mucho más evidente.

Hay que dejar claro, sin embargo, que para Henry esta preeminencia del tacto se debe sólo a que en él se hace más fácilmente accesible la motilidad que hace posible la unidad de las sensaciones. Pero, en ningún caso, esta preeminencia del sentido del tacto es ontológica en sí misma: «el movimiento es inmanente al ejercicio de cada uno de nuestros sentidos, y, por consiguiente el privilegio del tacto debe ser compartido por todos los demás sentidos...» ${ }^{43}$. No conocemos el mundo mediante un sentido, yendo los demás a la zaga del primero, sino que el conocimiento dado en las sensaciones forman una unidad o corriente en la que se destaca, por decirlo así, uno de los sentidos manteniéndose los demás como trasfondo de ese sentir particular. A partir de aquí, Henry muestra fenomenológicamente la unidad ontológica de nuestros sentidos. Retomando el ejemplo de Sartre en el cual se busca comprender qué relación hay entre la imagen visual que concibo al querer trazar una curva en el aire con mi dedo y el acto mismo de trazarla, Henry muestra cómo el movimiento de la mirada que pone en juego el sentido de la vista es el mismo movimiento que el de mi mano que traza la curva. No se trata de dos movimientos consecutivos ni de dos movimientos superpuestos ni de dos movimientos relacionados causalmente sino de un único movimiento «que es una unidad en la inmanencia absoluta de la subjetividad» ${ }^{44}$. Por tanto, tras aquella primera reducción de la sensación a un movimiento particular del cuerpo, aparece esta otra: la reducción de la diversidad de sensaciones a una unidad de movimiento en el cuerpo. Basta la descripción fenomenológica del acto de trazar una curva para mostrar que el ser es ya, en la inmanencia de la subjetividad del cuerpo, unidad de

${ }_{41}$ La importancia del sentido del tacto como comienzo mismo del análisis fenomenológico ha sido resaltado en: SAN MARTín, J., «Apuntes para una fenomenología del cuerpo» en Rivera de Rosales, J. y López SÁenz, M. del C. (coord.), El cuerpo. Perspectivas filosóficas, UNED Ediciones, Madrid, 2002, pp. 133-178.

42 Ricoeur, P., op. cit., p. 359.

43 Henry, M., Filosofía y fenomenología del cuerpo, op. cit., p. 125. La cursiva es del autor.

$44 \quad$ Ibid., p. 135. 
experiencia de movimiento. Es a esta experiencia, en la que el cuerpo sabe de sí cabe sí, a lo que llamamos sentir.

Esta manera de pensar el sentir tendrá unas implicaciones enormes para concebir otros temas que tradicionalmente han sido tratados por la fenomenología. Henry se centra en dos de ellos: la comprensión del cuerpo como hábito y como memoria. Si el sentir no lleva en sí la fugacidad ni la volatilidad de las sensaciones sino que es la unidad de movimiento del propio cuerpo subjetivo, entonces el sentir deja un saber permanente en el cuerpo que llamamos «memoria». Ahora bien, pese a darse en la inmanencia del cuerpo, no es un saber $a$ priori sino dado una y otra vez en la repetición de los actos promovidos por el cuerpo. Esta repetición, que hace referencia a la potencia de volver a realizar el mismo acto, y que proviene del movimiento infinito de la subjetividad, es el hábito ${ }^{45}$. Con ello Henry re-interpreta, en su fenomenología inmanente del cuerpo, el tema clásico del hábito que ya tratara Husserl, entre otros lugares, también en las Meditaciones cartesianas ${ }^{46}$.

Henry sigue los textos de Maine de Biran aplicándoles los principios hermenéuticos de su propia fenomenología, esa fenomenología que expuso profusa y técnicamente en L'essence de la manifestation. Sin embargo, el último capítulo de su libro se cierra con una crítica a Maine de Biran. Este filósofo francés no superó la sombra del dualismo cartesiano ni otros planteamientos extraños tomados de su época ${ }^{47}$. «Lo que tomó prestado de otros — llega a afirmar Henry-, es lo que es falso en su pensamiento ${ }^{48}$. Maine de Biran se dejó arrastrar por las posiciones metafísicas de su época respecto a la sensibilidad, la afectividad y la imaginación y, pese a su intento radical de pensar el yo como fuerza y poder, no supo dar con una teoría adecuada que sacara a luz el carácter originario de la subjetividad del cuerpo. Lo que él no encontró, y no pudo encontrar, fue el modo como despojar toda experiencia trascendente del cuerpo para vislumbrar la subjetividad absoluta inmanente. Para ello hubiera necesitado de una teoría ontológica de la pasividad y no ligar la pasividad, como apuntábamos más arri$\mathrm{ba}^{49}$, a aquello que no es inherente al yo.

Como se recordará, el tema de la síntesis pasiva es central en la fenomenología husserliana. Por ejemplo, en las Meditaciones cartesianas dice Husserl que «toda construcción por la actividad pre-supone como grado inferior una pasividad pre-donante $\aleph^{50}$. Es esta pasividad, que constituye el seno mismo de la subjetividad transcendental y que ha de ser presupuesta en toda otra actividad del sujeto, lo que, a la altura de su tiempo, Maine de Biran no pudo encontrar.

45 Sobre el sentido de la habitude en este texto de Henry se ha detenido: FaInSTEIN LAmuedra, G., "Michel Henry y la teoría ontológica del cuerpo» en Investigaciones fenomenológicas, número monográfico 2, 2010, pp. 239-240.

46 Husserl, E., op. cit., pp. 89-90.

47 Cfr. GaRcía JaRAMa, J. C., op. cit., p. 373.

48 Henry, M., Filosofía y fenomenología del cuerpo, op. cit., p. 219.

49 Cfr. nota 20.

50 Husserl, E., op. cit., p. 104. 
Es esta vida pasiva, que acontece en el interior de la esfera de la subjetividad, la que es propia de nuestro cuerpo inmanente; esto es, de ese cuerpo que se vive, sin experiencia trascendente alguna, como carne. Pero esta tesis parece entrar en conflicto con otra que ya hemos expuesto: la que define la esencia de nuestro cuerpo subjetivo como motilidad y, por tanto, también, como actividad. ¿Pueden conciliarse ambas tesis? ¿Puede conciliarse, al mismo tiempo, actividad y pasividad en el seno de la subjetividad? De no poder hacerlo, ¿en qué modalidad reside entonces el poder o la potencia del cuerpo? Pensar que actividad y pasividad son dos modalidades diferentes del cuerpo subjetivo es pensar todavía, parece indicarnos Henry, bajo el signo del dualismo cartesiano, aceptado acríticamente por Maine de Biran. Es cierto que en el movimiento de nuestro cuerpo se pone en juego nuestra capacidad para actuar y que en la vida pasiva se pone en juego nuestra capacidad para sentir; pero, el actuar y el sentir, vistos desde la originariedad de la experiencia interna de la subjetividad, no son, en modo alguno, formas heterogéneas de una misma subjetividad sino, al modo spinozista, «dos modalidades diferentes de un único y mismo poder fundamental que no es sino el ser originario del cuerpo subjetivo» ${ }^{51}$. Es este ser originario, que ora se nos muestra en movimiento y ora retraído de todo movimiento, un único ser que experiencia cabe sí la vida en su propia carne, porque vida es la experiencia del movimiento que lleva a nuestro cuerpo a impregnarse de la realidad trascendente del mundo, vida es la experiencia de dejarse impregnar sintiendo esa realidad, pero vida es sobre todo la experiencia del vivir y del dejarse vivir por la subjetividad que nuestra carne lleva dentro. Quizás, si nuestro cuerpo es vivido así, el sentir, que en esta era de la estética ha sido banalizado, mercantilizado y rebajado para ser utilizado por otros poderes que no son los del propio cuerpo, puede elevarse en su inmanencia - no hay ya paradoja en la proximidad de estos términos- a la dignidad que el pensamiento filosófico, teológico y científico, a menudo, le negó. La fenomenología radical de Michel Henry nos marca un camino para pensar ontológicamente el cuerpo como aquello que llevando en sí el sentir opera la apertura en la subjetividad actuante en el hombre. Si esto es así, en el sentir, entonces, radica la experiencia originaria donde el pensamiento ha de acudir, como a la fuente envejecida y herrumbrosa que se resquebrajará en el paso del tiempo, para beber el agua que primordialmente brota, se manifiesta y se derrama de la Vida invisible que no muere.

Universidad de Murcia

Agustín Palomar Torralbo

Departamento de Filosofía

agupalomar@yahoo.es

[Aprobado para publicación en noviembre de 2013]

51 Henry, M., Filosofía y fenomenología del cuerpo, op. cit., p. 229. 